\title{
Study on the Evaluation of Economic Support Index for Pig Breeding in Water Network Area of Middle Reaches of Yangtze River
}

\author{
Bi-Bin Leng, Qi -zhen Zhang, Wen-wei Lai and Xin-Fan Tang \\ Jiangxi Science \&Technology Normal University, Nanchang, China
}

\begin{abstract}
The central region of China boasts a long history, abundant resources, convenient transportation, advanced economy, a strong industrial and agricultural foundation and a rapid development of modern service industry, with about $10.7 \%$ of the country's total land area, $26.5 \%$ of the country's population and a GDP of about $21.4 \%$ of the country's total. As the population center, transportation hub, economic hinterland and important market, it is the second echelon of China's economic development; the central region of China plays an important role in the division of labor in China. The middle reaches of the Yangtze River water network includes four neighboring provinces- Hubei, Hunan, Anhui and Jiangxi. Although all four provinces are located in the middle of the Yangtze River Basin, there are still quite some differences. Based on the 2017 Statistical Yearbook data, this paper studies the economic supportive index of pig breeding in four provinces located in the water network area of the middle reaches of the Yangtze River in Jiangxi, Hubei, Hunan and Anhui. The evaluation results show that among the four provinces, the socio-economic conditions of Hubei Province can most support the large-scale cultivation of live pigs, and the support of Jiangxi Province is the weakest.
\end{abstract}

\section{Introduction}

The Ministry of Finance, the Ministry of Environmental Protection, and the State Administration of Taxation issued a joint notice that the preparation for the collection and management of environmental protection tax was fully started and the Environmental Protection Tax Law was formally implemented on January 1, 2018. The implementation of the environmental tax law is a severe test for the breeding industry, which also means that the country pays much attention to the livestock breeding issue. Pig breeding is the top industry in animal husbandry. Inevitably, there will be a large number of "public hazards of livestock production", such as poultry excrement and aquaculture sewage which are arbitrarily dumped and discharged, and the environment is deteriorating in the concentrated areas where livestock farms are located, indirectly contaminating water sources and soil air.

The four provinces of Jiangxi, Hubei, Hunan, and Anhui are in the middle of the inland and coastal areas, and have become important links and bridges between inland and coastal cities. With the advantages and resources of the economic belt of the upper reaches of the
Yangtze River and the economic belt of the lower reaches of the Yangtze River, these four provinces have become the "hearts" of China's economic geography. Based on the data of 2017 statistical yearbook, this paper uses the analytic hierarchy process to evaluate the economic support index of pig-scale aquaculture in the four provinces of the middle reaches of the Yangtze River.

\section{Index determination and calculation}

With reference to the existing literature, when the average GDP per capita, industrial enterprise research and experimental development expenditure equal to the ratio of regional GDP and total pork production are taken as evaluation indicators, the economic support of live pigs in six provinces in Central China is evaluated. According to the data of the 2017 statistical yearbook, the evaluation index of the economic support index for the scale pig breeding scale are calculated as Z1, Z2, and Z3, which are shown in Table 1: 
Table 1. Calculation and Standardization of Economic Support Index of Live Pig Breeding in Four Provinces in the Middle Reaches of the Yangtze River in China

\begin{tabular}{cccc}
\hline Province & $\begin{array}{c}\text { Regional Product Value } \\
\text { per capita with } \\
\text { Dimensionless Process } Z_{1}\end{array}$ & $\begin{array}{c}\text { R\&D Expense of } \\
\text { Industrial Enterprises } \\
\text { Share of Regional GDP } \\
\text { with Dimensionless } \\
\text { Process } Z_{2}\end{array}$ & $\begin{array}{c}\text { Pork Production with } \\
\text { Dimensionless Process } Z_{3}\end{array}$ \\
\hline Anhui & 0.71 & 1.00 & 0.56 \\
Jiangxi & 0.72 & 0.63 & 0.56 \\
Hubei & 1.00 & 0.90 & 0.74 \\
Hunan & 0.83 & 0.81 & 1.00 \\
\hline
\end{tabular}

Based on the table above, the descriptiveness of social and economic support indicators is further calculated and analyzed as shown in Table 2 below:

Table 2. Descriptive statistics

\begin{tabular}{cccccc}
\hline & N & Minimum & Maximum & Mean Value & $\begin{array}{c}\text { Standard } \\
\text { Deviation }\end{array}$ \\
\hline $\mathbf{Z 1}$ & 4 & .71 & 1.00 & .8150 & .13478 \\
$\mathbf{Z 2}$ & 4 & .63 & 1.00 & .8350 & .15716 \\
$\mathbf{Z 3}$ & 4 & .56 & 1.00 & .7150 & .20809
\end{tabular}

Valid N (the list state)

4

Table 2 shows the descriptive statistics of the economic support indicators. Combining the data with that of table 1, we can see that the standard deviation of regional GDP per capita is small, and the degree of sample dispersion is low. The per capita GDP of Hubei is the highest; and the average per capita GDP of Anhui Province and Jiangxi Province are below the average value. As for the research expenditure of research and development of industrial enterprises share of regional GDP, Anhui owns the largest value, while Jiangxi owns the smallest one. And the indexes of Jiangxi and Hunan is below the average level. The standard deviation of total pork production is large, and the sample has a high degree of dispersion. Hunan has a maximum value while Jiangxi and Anhui own the smallest value. Besides, the indexes of these two provinces is below the average.

\section{Evaluation on the economic support index of live pig breeding in four provinces in the middle reaches of the Yangtze River}

After analyzing that factors analysis method for evaluation indexes of live pigs' scale aquaculture economic support index in six provinces in central China is applicable, we performed factor analysis on the indicators and obtained the factor variance contribution rate as shown in Table 3.

Table 3. Factor variance contribution rate

\begin{tabular}{|c|c|c|c|c|c|c|c|c|c|}
\hline \multirow[t]{2}{*}{$\begin{array}{c}\text { Compo } \\
\text { nent }\end{array}$} & \multicolumn{3}{|c|}{ Initial Egigenvalues } & \multicolumn{3}{|c|}{$\begin{array}{l}\text { Extraction Sums of Squared } \\
\text { Loadings }\end{array}$} & \multicolumn{3}{|c|}{$\begin{array}{l}\text { Rotation Sums of Squared } \\
\text { Loadings }\end{array}$} \\
\hline & $\begin{array}{c}\text { Summatio } \\
\mathrm{n}\end{array}$ & $\begin{array}{c}\text { Of } \\
\text { Variance } \\
\%\end{array}$ & $\begin{array}{l}\text { Accumula } \\
\text { tion } \%\end{array}$ & $\begin{array}{l}\text { Summatio } \\
\mathrm{n}\end{array}$ & $\begin{array}{c}\text { Of } \\
\text { Variance } \\
\%\end{array}$ & $\begin{array}{l}\text { Accumula } \\
\text { tion } \%\end{array}$ & $\begin{array}{l}\text { Summatio } \\
\mathrm{n}\end{array}$ & $\begin{array}{c}\text { Of } \\
\text { Variance } \\
\%\end{array}$ & $\begin{array}{l}\text { Accumula } \\
\text { tion } \%\end{array}$ \\
\hline 1 & 1.524 & 50.810 & 50.810 & 1.524 & 50.810 & 50.810 & 1.466 & 48.876 & 48.874 \\
\hline 2 & .995 & 33.153 & 83.963 & .995 & 33.153 & 83.963 & 1.053 & 35.090 & 83.963 \\
\hline 3 & .481 & 16.037 & 100.000 & & & & & & \\
\hline
\end{tabular}

The factor variance after the extraction is very high, indicating that the extracted factors can best describe these three indicators. The variance contribution rate of factor 1 is $50.810 \%$; the characteristic value is 1.524 ; the variance contribution rate of factor 2 is $33.153 \%$ and the characteristic value is 0.995 . These two indexes explain $97.047 \%$ (more than $80 \%$ ) of the variance, so we extracted the first two components as the first and second principal components. Therefore, we get Table 4 below: 
Table 4. Component Matrix ${ }^{\mathrm{a}}$

\begin{tabular}{lcc}
\hline & \multicolumn{2}{c}{ Component } \\
\cline { 2 - 3 } & 1 & 2 \\
\hline $\mathbf{Z 1}$ & .871 & -.009 \\
$\mathbf{Z 2}$ & .371 & .907 \\
$\mathbf{Z 3}$ & .793 & -.415 \\
\hline
\end{tabular}

As shown in Table 4, the first component has the that the variables $Z 1$ and $Z 3$ are mainly explained by the maximum load on variables $\mathrm{Z} 1$ and $\mathrm{Z3}$, and the correlation coefficients are 0.871 and 0.793 respectively; the second component has the maximum load on Z2 with the correlation coefficient as 0.907 . It can be concluded first principal component, and $\mathrm{Z} 2$ is mainly explained by the second principal component. The following factorial rotation factors are shown in Table 5 below:

Table 5. Rotating component matrix

\begin{tabular}{lllr}
\hline & \multicolumn{3}{c}{ Component } \\
\cline { 2 - 4 } & 1 & & 2 \\
\hline $\mathbf{Z 2}$ & & .050 & .979 \\
$\mathbf{Z 1}$ & .825 & .280 \\
$\mathbf{Z 3}$ & & .885 & -.129 \\
\hline
\end{tabular}

The results obtained after the rotation are shown in Table 5. The maximum load of component 1 on the variables $\mathrm{Z} 1$ and $\mathrm{Z} 3$ was 0.825 and 0.885 respectively. The maximum load of component 2 on $\mathrm{Z} 2$ was 0.979 .
Component 1 can be named as F1 and component 2 as F2. Therefore, the factor score coefficient matrix is as shown in Table 6.

Table 6 .Component Score Coefficient Matrix

\begin{tabular}{|c|c|c|c|}
\hline & & \multicolumn{2}{|c|}{ Component } \\
\hline & & 1 & 2 \\
\hline $\mathbf{Z 1}$ & & .542 & .181 \\
\hline $\mathbf{Z 2}$ & & -.072 & .941 \\
\hline $\mathbf{Z 3}$ & & .629 & -.222 \\
\hline $\begin{array}{l}\text { ch factor expressio } \\
.542 * Z 1-0.072 * Z \\
.181 * Z 1+0.941 * \\
\text { rst two variance co } \\
3 \% \text { ) were normaliz } \\
\text { riance contribution } \\
\text { t, and the environn }\end{array}$ & $\begin{array}{l}10 \% \text {, } \\
\%) . \text { Take } \\
\text { vas the } \\
\text { ng index } \\
7 . \text { Social }\end{array}$ & $\begin{array}{l}\text { was obtained as follows } \\
Y=60.515 \% * F 1+39.4 \\
\text { Factor scores and } \\
\text { in Table } 7 \text { below. }\end{array}$ & ndexes are shown \\
\hline Province & $\mathrm{F} 1$ & $\mathrm{~F} 2$ & $\mathrm{Y}$ \\
\hline Anhui & 0.66506 & 0.94519 & 0.77567 \\
\hline Jiangxi & 0.69712 & 0.59883 & 0.65831 \\
\hline Hubei & 0.94266 & 0.86362 & 0.91145 \\
\hline Hunan & 1.02054 & 0.69044 & 0.89020 \\
\hline
\end{tabular}

The following figure shows the socio-economic support index $\mathrm{Y}$ in the Central Region: 


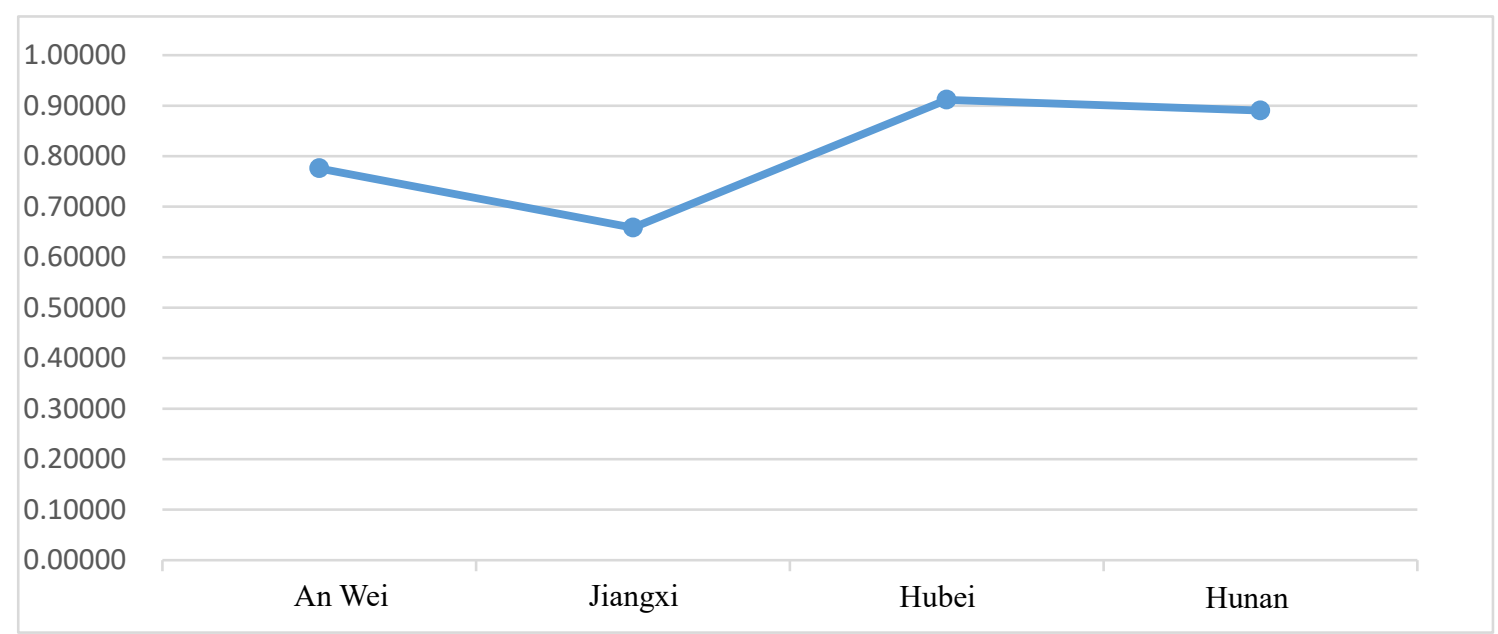

Chart 1. Line chart of environmental bearing capacity index of live pigs in four provinces in the middle reaches of the Yangtze River

As shown in the figure, Hubei has the highest socio-economic support index, followed by Hunan Province, Anhui Province, and Jiangxi Province. The lowest is Jiangxi Province. It shows that among the four provinces in the middle reaches of the Yangtze River, the social and economic conditions in Hubei Province can best support the scale breeding of live pigs, while Jiangxi Province has the weakest support.

\section{Conclusion}

With the intensification of market competition and people's increasing demand for quality of animal products, the scale of aquaculture has continued to increase. As a result, the pig breeding industry has become the top industry in animal husbandry. Inevitably, there will be a large number of "public hazards of livestock production". Animals and poultry excrement and aquaculture sewage are arbitrarily dumped and discharged, and the environment is deteriorating in the areas where livestock farms are concentrated, indirectly contaminating water sources and soil air.

The four provinces in the middle reaches of the Yangtze River water network - Jiangxi, Hubei, Hunan , and Anhui are in the middle of the inland and coastal areas, and have become important links and bridges between inland and coastal cities. With the advantages and resources of the economic belt of the upper reaches of the Yangtze River and the economic belt of the lower reaches of the Yangtze River, Hunan, Jiangxi, Hubei and Anhui have become the "hearts" of China's economic geography. Based on the data of 2017 statistical yearbook, this paper uses the analytic hierarchy process to evaluate the economic support index of pig-scale aquaculture in the four provinces of the middle reaches of the Yangtze River. The evaluation results show that Hubei Province has the highest index of economic support, followed by Hunan Province, Anhui Province, Henan Province and Jiangxi Province, and the lowest is Shanxi Province.

\section{References}

1. China Statistical Yearbook [M]. Beijing: China Statistics Press, 2017.

2. China Animal Husbandry Statistics Yearbook [M]. Beijing: China Agriculture Press, 2017.

3. National Pig Production Development Plan (2016-2020) [J]. China Agricultural Information, 2017(01):16-22.

4. Li Zhigang, Leng Bibin, $\mathrm{Tu}$ Guoping Comprehensive Evaluation of Environmental Bearing Capacity of Livestock Breeding Scale [J].Journal of Anhui Agricultural Sciences, $2014,42(27): 9382-9385+9471$.

5. Meng Xianghai, Zhang Juntao, Li Peng, Chen Xiaokun Summary of Environmental Pollution and Environmental Governance Policies in Animal Husbandry [J]. Journal of Ecology and Rural Environment,2014,30(01):1-8. 